\title{
A Reformulação Curricular do Curso de Medicina da Universidade de Buenos Aires (1986-2002)
}

\author{
Curricular Reform at the University \\ of Buenos Aires School of Medicine \\ (1986-2002)
}

PAI.AVRAS-CHAVE

- Educação médica;

- Educação superior;

- Currículo; Argentina

KEY-WORDS

- Education, medical;

- Education, higher;

- Curriculum, Argentina.

Recebido cm: 03/10/2002 Aprovado $\mathrm{cm}:$ 16/01/2003
${ }^{1}$ Pedagoga, Mestre em Saùde Pública, Escola Nacional de Saúde Priblica, Fundaçdo Osualdo Cruz, Doutora em Sutude Pública, Escola Nacional de Saúde Pública, Fundaçio Osualdo Cruz, Rio de Janeiro. Este artigo faz parte da pesquisa de doutonado realizada com bolsas CNPq e Capes. 


\section{INTRODUÇÃO}

Este trabalho tem como questão central o processo de reformulação curricular do curso de Medicina da Faculdade de Medicina da Universidade de Buenos Aires (UBA). E, para compreendê-lo, é necessário entender o contexto que lhe serve como pano de fundo, afetando e determinando a dinâmica tanto interna quanto externa à instituição: o da mudança na relação e no contrato social, que se produz na década de noventa, entre o Estado e a universidade.

No processo de reformulação curricular da Medicina da UBA, percebemos diversos eixos que conformam uma rede de influências e convergências de fatores que determinaram seu desenvolvimento e entraves, respectivamente.

Quais seriam tais eixos?

OEstado, Estado de Bem-Estar, Cultura Reformista, Mercosul, Políticas Públicas, Lei de Educação Superior, Relação do Estado com a Universidade.

Alguns dos eixos que atravessam a realidade estudada são a mudança de um Estado de Bem-Estar para um Estado avaliador, seus reflexos na Lei de Educação Superior de 1995 e as propostas do Mercosul Educativo, a dinâmica interna própria das universidades públicas argentinas, guiadas pela Reforma de $1918^{*}$, nas quais a disputa política está atravessada pela disputa político-partidária (fundamentalmente a partir de $1983^{* *}$ ), e a dimensão pedagógica — que faz com que os profissionais da área de educação nessa Faculdade de Medicina gozem de grande prestígio e indiquem os caminhos a seguir nos processos de reformulação curricular da Medicina. Cada uma das peças acima fez parte do quebra-cabeças e conformou (e conforma) o processo de reformulação curricular da Faculdade de Medicina da UBA.

\section{O ESTADO AVALIADOR, AS REFORMAS DAS UNIVERSIDADES E O PAPEL DAS AGÊNCIAS INTERNACIONAIS}

Consideramos que o processo de reformulação curricular se encontra refletido na mudança que se produz a partir da década de noventa: o Estado de Bem-Estar, no âmbito educativo, é substituído por um Estado avaliador. Para o Estado de

"Do ponto de vista histórico, o movimento estudantil da Reforma deu d̀s unitversidades argentinas (e latino-americanas) seu estilo organizacional: o co-governo de estudantes, professores e graduados - corpos colegiados que representam os três estanentos para tomar as decisjes; os concursos de docentes; cátedras paralelas; atividades de extensĩo universitária inseridas no meio social; a organizaghlo de centros de estudantes com atividades para atender às demandas dos alunos, tanto administratious (fotocópias, publicapues, horírios, ofertas de cursos, etc.) quanto politicas (Mollis, 1995).

"A disputa politica se transforma em disputa politico-partidária a partir de 1983, quando se constata uma clara hegemonia do partido politico UCR (Unialo Civica Radical) nos órgäos de governo da UBA.
Bem-Estar, a universidade era "uma instituição social, com ação e prática social fundada no reconhecimento público de sua legitimidade e de suas atribuições, num princípio de diferenciação que the conferia autonomia perante outras instituições sociais e estruturada por ordenamentos, regras, valores de reconhecimento e legitimidade internos a ela, com autonomia do saber em face da religião e do Estado" ${ }^{\prime 1}$. E o que passa a ser a universidade para este novo Estado avaliador?

Nas últimas duas décadas, os governos da América Latina têm adotado regimes neoliberais, que vêm reestruturando seus sistemas de educação. Esse processo estabeleceu-se a partir de uma série de medidas comuns à região: "ajuste da oferta" (redução do investimento público na educação); "reestruturação jurídica do sistema" (novas leis de educação); e "profunda redefinição do papel do Estado do ponto de vista educacional" (saindo da função social de educar e assumindo o papel de fiscalizador e avaliador). "Políticas de descentralização e transferência, reformas curriculares, mudanças significativas na gestão escolar e na formação docente (...) implementadas pelos governos neoliberais latino-americanos com apoio de alguns organismos internacionais - como o Banco Mundial ou o Banco Interamericano de Desenvolvimento"2.

Para Roberto Leher, "o Banco Mundial determina que o modelo europeu de universidade - estatal, autônoma, pública, gratuita e baseada no princípio da indissociabilidade entre ensino, pesquisa e extensão - não é compatível com a América Latina" ${ }^{3}$.

Desde a década de noventa, a substituição do chamado Estado de Bem-Estar por um Estado que avalia a prestação dos serviços, mas descentraliza a administração educativa, teve muito impacto sobre as dinâmicas de poder econômico e político. E promoveu, nos sistemas de educação superior latino-americanos, profundas mudanças e reformas ${ }^{4}$.

O periodo das reformas neoliberais na América Latina, desde a reforma educacional desenvolvida no Chile, expandiu-se progressivamente a quase todos os países da região. A partir da recuperação democrática destes países, algumas universidades públicas foram consolidando respostas adaptativas às demandas de uma agenda internacional promovida pelo Banco Mundial e mais tarde pelo Banco Interamericano de Desenvolvimento (BID) (México, Colômbia e Argentina), mas houve, também, severas resistências institucionais (Bolívia e Brasil) $)^{5}$.

Nas universidades, as pressões externas dos organismos internacionais têm orientado a diversificação de fontes de financiamento (venda de serviços e cobrança de taxas escolares), reformas curriculares (encurtamento dos cursos de graduação para obter mais rápida inserção no mercado de traba- 
lho), seletividade no acesso (exames tipo vestibular), promoção de novos cursos orientados para o mercado (Marketing, Finanças, Sistemas, etc.), atualização docente e rápida expansão de universidades particulares. Estas tendências formam parte de uma "agenda internacional" que se aplica na América Latina (e nos países pós-socialistas da Europa) e constituem o contexto internacional em que se inserem as reformas atuais na Argentina ${ }^{4}$.

Acreditamos que as recomendações do Banco Mundial, e de outras agências internacionais, vêm influenciando a construção das políticas educacionais do Mercosul. A avaliação e o credenciamento universitários constituem pontos fundamenais para entender as tendências mundializantes em matéria de políticas para o campo da educação superior na Argentina. E aparecem no contexto da reformulação do currículo da medicina.

No caso específico estudado, percebemos que as várias propostas de modificação no currículo e de reformulação curricular estiveram vinculadas às modificações do panorama mundial (mundialização) e refletidas na Argentina - e em toda a região - pelas políticas neoliberais. Um exemplo ilustrativo neste caso é o da promulgação da Lei de Educação Superior (Lei N² 24.521 de 1995) ${ }^{6}$ com a introdução de mecanismos centralizados de avaliação e credenciamento universitários (através da Comissão Nacional de Avaliação e Credenciamento Universitário, ${ }^{*} \mathrm{Coneau}^{7} \mathrm{e}$ Secretaria de Políticas Universitárias) e seu impacto na autonomia universitária.

Outro exemplo do impacto da citada lei e suas conexões / interfaces com a administração do decano da faculdade de medicina da época foi a aprovação do artigo $\mathrm{N}^{0} 50$, que estabelece que "nas universidades com mais de cinqüenta mil (50.000) estudantes, o regime de admissão, permanência e promoção dos estudantes será definido ao nível de cada faculdade ou unidade acadêmica equivalente". Tal modificação significou, entre outras, uma mudança muito importante em um dos princípios da Reforma de 1918, característico das universidades argentinas: o ingresso democrático, direto e sem limite de vagas para as universidades públicas.

Para entender a dinâmica na qual a universidade argentina se insere e sua forma de organização, tanto no aspecto do ingresso dos estudantes quanto em outros, é necessário reme-

\footnotetext{
*A Coneau tem a funçño de atoaliagño institucional de todas as universidades nacionais, provin* ciais e particulares; o credenciamento de pós-graduaçues e cursos regulares c a emissăo de reco. mendaģes sobre os projetos institucionais de novas unizersidades estatais e da autorizaçulo provisória e definitiva de estabelecimentos universitários privados. Possui, também, a funçlo de emitir parecer sobre o reconhecimento de entidades particulares de ataliaģão universitária. Tem mandato legal para realizar as seguintes tarefas; awaliaçôes externas; credenciamento de cursos de graduaglo; credenciamento de cursos de pús-graduaçäo; atualiap̧o de projetos institucionais; reconhecimento de entidades particulares.
}

ter-se à eforma de 1918. Em todos os relatos de reunióes e das entrevistas realizadas, esteve presente a idéia do marco dos princípios da Reforma de Córdoba (1918). Fosse para resgatálos ou tentar superá-los, os princípios da Reforma podem ser considerados norteadores da estrutura universitária argentina, registrados em seu estatuto interno.

$\mathrm{Na}$ atual situação, em que o processo de mundialização em curso parece aprofundar a polaridade entre ricos e pobres, a América Latina desempenha um papel subordinado, de periferia. E, dentro da América Latina, Argentina e Brasil ocupam um lugar central na nova agenda modernizante, através do Mercosul, uma das estratégias para a implementação dessa nova agenda. A seguir, faremos uma rápida descrição do Mercosul e de suas influências nas discussōes e reformulaçōes curriculares.

\section{ESTADO E REGIONALIZAÇÃO: AS POLÍTICAS DO MERCOSUL}

Um dos traços destacados da mundialização capitalista na última década foi o aparecimento e consolidação de blocos econômicos regionais destinados a aumentar os níveis de intercâmbio comercial e de integração econômica regional. Os casos da União Européia, o Acordo de Livre Comércio da América do Norte, o bloco dos países do Sudeste Asiático e o Mercado Comum do Sul (Mercosul) constituem os exemplos mais visíveis dessa tendência, mesmo que apresentem notórias diferenças em suas dinâmicas e níveis de integração. A evolução destes processos - e compreensão de suas conseqüências sociais - não pode estar desligada da hegemonia política e econômica do neoliberalismo.

Neste sentido, cabe assinalar que a evolução recente dos processos de integração - alguns deles de longa data, como no caso da União Européia - tem estado ligada de forma direta ao que genericamente podemos chamar de "ideologia de mercado" e que, em muitos casos, estes processos vêm servindo para veicular ou aprofundar, em espaços regionais mais amplos, os preceitos econômicos ligados à mercantilização dos bens públicos**.

A partir de meados da década de 80 , os países do cone sul da América Latina foram protagonistas de uma experiência de integração até então inédita na região: o Mercosul.

Esse processo de integração, que adotou desde o início a forma de uma união aduaneira imperfeita, atravessou dife-

\footnotetext{
"No caso curopeu, por exemplo, a disciplina fiscal exigida pelos acondos de Maastricht e de Amsterda para a construçăo da moeda ủnica (o euro) serviu como ferramenta para a aplicaçāo de políticas orgamentírias ortodoxas em escala nacional, que tiveram um considerível impacto na retraça do gasto público e no debilitamento dos direitos sociais e trabullistas conquistados pelos assalariados depois da Segunda Guerra Mundial.
} 
rentes fases ligadas à evolução econômica de seus respectivos integrantes (fundamentalmente Brasil e Argentina) à luz do impacto das políticas econômicas neoliberais. Independentemente das expectativas iniciais - no sentido de que o Mercosul poderia constituir uma experiência de integração regional que priorizara um modelo de desenvolvimento autônomo na região -, o impacto crescente das políticas econômicas liberais e o impacto das sucessivas crises financeiras internacionais que afetaram o Brasil e, na atualidade a Argentina, fizeram com que o processo de integração perdesse impulso. Principalmente a partir de 1999 e da desvalorização da moeda brasileira, que afetou os termos de intercâmbio comercial entre os dois sócios principais, que se encontra hoje numa profunda crise. Diante desta realidade e das frustradas expectativas iniciais de integração em diferentes âmbitos que excediam o mero marco do intercâmbio comercial (educação, cultura, etc.), é preciso indagar-se sobre as "promessas não cumpridas" do Mercosul, que tanta expectativa geraram em âmbitos oficiais e acadêmicos.

Tentar responder a estas questões significa historiar o processo e tentar identificar os diferentes ciclos que caracterizaram esta experiência, assim como também os diferentes interesses envolvidos no processo de integração. Não é o objetivo deste trabalho realizar uma análise pormenorizada da evolução econômica do Mercosul. Entretanto, à luz das tentativas de harmonização de políticas universitárias que foram incentivadas desde a assinatura do Tratado de Assunção em 1991, acreditamos que seja importante questionar sobre o impacto - se existe - que as políticas de educação superior do Mercosul, através das discussões do Mercosul Eucativo, tiveram e/ou têm no processo de reformas curriculares e nos processos de harmonização do credenciamento de títulos universitários. Nosso universo de análise, como assinalamos na primeira parte deste trabalho, se constitui no processo de reformulação curricular na Faculdade de Medicina da UBA. Partindo das discussões esboçadas nas comissões técnicas de educação superior, do chamado Mercosul Educativo*, nos interessa analisar se existe alguma influência dos debates e recomenda-

\footnotetext{
"Em 1991, o Conselho do Mercado Comum criou a Reuniño de Mintistros de Educação. Com a assessoria do Comite Coordenador Regional, composto pelos representantes oficiais dos governos na área educacional, esta reuniăo tem como funçlo propor medidas que coordenem as polilicas educacionais dos estados membros e os Planos de Açăo. Desde entīo, passaram a realizarSe reuniōes semestrais de Ministros de Educação - alternando-sc a presidíncia de cada reunĭo - e nunides do Comite Coordenador Regional (composto por 12 membros permanentes, sendo trés por pais). Ao Comité compete a organizaģalo das principais pautas e os temas técnicos a serem descntolvidos pelos especialistas, ao longo de cada semestre. Foram constituidas diversas comissỏes de trabalho para tratar de vários temas especificos da área educatitu. Nas comissoles, foi definida, por exemplo, a necessidade de estabelecer diretrizes curriculares a partir das quais. todas as faculdades de medicina devem se basear para elaborar e reformular seus curriculos.
}

ções destes âmbitos no processo de reforma curricular, dentro da estratégia de homogeneização dos países "periféricos".

$\mathrm{Na}$ área médica, já foram definidas as diretrizes curriculares a serem seguidas por todas as faculdades de medicina dos países membros do Mercosul. A que demanda atenderão tais diretrizes e até que ponto serão implementadas por todas as faculdades, públicas ou privadas?

No caso da Faculdade de Medicina da UBA, cada processo de reformulação obedeceu a uma lógica, dependendo das lideranças que o impulsionassem. No processo anterior (interrompido em agosto de 2000), a idéia era seguir as indicações do Mercosul Educativo com relação às diretrizes curriculares, e, em geral, o trabalho acompanhou as modificações previstas pela Lei de Educação Superior, em coerência com os delineamentos dos organismos internacionais em indicações para a América Latina.

Já no atual processo de reformulação curricular, iniciado em dezembro de 2000, não foram discutidas especificamente as ditas questões nas reuniōes realizadas durante 2001, nem foi explicitado o seguimento ou não de tais princípios (nos aprofundaremos no decorrer do artigo).

A partir de nossa observação participante nas reuniōes de reformulação curricular, realização de entrevistas com informantes-chave dos processos desenvolvidos durante as duas últimas décadas e leitura de material levantado (fontes primárias e secundárias), verificamos que os processos vêm sendo perpassados por vários eixos (já mencionados) e faremos a análise levando em conta sua interface.

Passaremos a relatar o caso específico da reformulação curricular da Faculdade de Medicina da UBA, incluindo seus antecedentes históricos e especificidades.

\section{REFORMULAÇÃO CURRICULAR DA FACULDADE DE MEDICINA DA UBA (1986-2002)}

A Faculdade de Medicina da Universidade de Buenos Aires (UBA), nas últimas duas décadas, sofreu várias tentativas de reformulação curricular. Desde 1983, com a volta à democracia, a faculdade passou por diversos movimentos de reformulação curricular e, desde 1986, pela implantação de inovações curriculares. $\mathrm{O}$ mais recente processo de reformulação curricular tem dois momentos: o primeiro durante os anos de 1999 e 2000, e o segundo a partir de dezembro de 2000 até a presente data. Cada momento se relaciona com a gestão de dois diferentes decanos.

Buscaremos contextualizar o processo vivido desde a década de oitenta, na tentativa de relatar a origem dos dois mais recentes momentos e seu desenvolvimento, incluindo, ainda, as características do modelo de autonomia universitária, o tipo 
de direção e administração das faculdades da UBA e - como se denomina na Argentina - o governo autônomo das universidades públicas, mais especificamente o governo da UBA. Consideramos que tal relatoé importante para a contextualização e compreensão dos processos com suas particularidades.

\section{A Gestão da UBA e a Volta à Democracia}

A UBA, assim como a maioria das universidades nacionais argentinas, seguindo os delineamentos da Reforma de 1918, tem organização acadêmica em forma de cátedras e faculdades. Os Conselhos Diretivos das Faculdades são eleitos por votação direta dos diferentes "claustros"*, onde estão representados os professores, os graduados e os estudantes. Os conselhos, por sua vez, elegem os decanos das faculdades.

Os membros dos órgãos colegiados superiores da universidade também são resultado de eleiçōes dos diferentes "claustros". O Conselho Superior - integrado pelo reitor, decanos e representantes dos professores, graduados e estudantes compõe, junto com os membros dos conselhos diretivos, a assembléia universitária, que elege, por sua vez, o reitor.

Segundo depoimentos de professores e alunos da Faculdade de Medicina da UBA (em entrevistas realizadas durante 2000 e 2001), o curso de medicina, desde 1986, vem discutindo a necessidade de reformar seu currículo.

Em 1983, com a volta da democracia e após anos de ditadura militar, que afetaram profundamente a administração das universidades públicas argentinas, o novo governo determinou a designação de decanos ${ }^{* *}$ normalizadores ${ }^{8}$, que, no prazo de dois anos, deveriam normalizar o funcionamento das faculdades e abrir concursos para professores. $\mathrm{O}$ decano normalizador da Faculdade de Medicina nesse período foi o Dr. Fernando Carlos Matera (1984-86).

Foi necessário um período de normalização porque, com os golpes militares, nas décadas de 60 e 70, as universidades públicas sofreram intervenção. Os interventores designados suprimiram os corpos colegiados e assumiram suas faculdades, modificando os estatutos e demais corpos normativos das respectivas universidades. Foi a clausura da autonomia universitária.

Os interventores, com atribuições para colocar à disposição aleatoriamente os cargos universitários, praticaram a remoção de autoridades e deixaram fora das universidades um número significativo de docentes, funcionários e estudantes. Foram suprimidas unidades acadêmicas, cursos e disciplinas

\footnotetext{
"Os claustros se referem aos grupos de representantes dentro dos conselhos (diretivv e superior). aos corpos colegiados que representam os trés estamentos para tomar as decisỏes: claustros de professores, estudantes e graduados.

-Em outros periodos de pós-ditadura também foram indicados decanos normalizadores.
}

nas universidades públicas, e modificados planos e programas de estudo. As áreas mais afetadas foram as das ciências sociais e as ciências básicas. Foram eliminados muitos dos princípios reformistas (da reforma de 1918): voltou a fortalecer-se a estrutura em faculdades fragmentadas em cursos e se reverteu a tendência a flexibilizar os currículos, que se tornaram mais rígidos e controláveis 9 .

Outras modificações foram impostas, como a diminuiçã̃o do gasto público em educação superior, cobrança de taxas e mensalidades nas universidades, redução das matriculas e das vagas, e a proliferação de instiuições particulares de ensino superior (universitárias ou não).

Como, então, se poderia realizar a tarefa de redemocratizaçăo das universidads?

Estes fatos fizeram com que, a partir de 1984, as universidades argentinas tivessem que passar por um longo trabalho de restauração das condições acadêmicas e de administração para recuperar sua autonomia e capacidade de criação e transmissão do conhecimento'.

De 1976 a 1982, a UBA teve o ingresso de estudantes restringido e decanos impostos pelo presidente (militar) da República. Além disso, muitos professores e estudantes foram perseguidos, torturados e mortos, além de tantos outros que foram proibidos de trabalhar na universidade. Com a volta da democracia, foi necessário reestruturar o corpo docente e reorganizar as faculdades. Dentre as medidas de reorganização, foi criado o Ciclo Básico Comum, em 8 de agosto de 1984. Através do expediente $\mathrm{n}^{2} 29.459 / 84$, o Conselho Superior da Universidade de Buenos Aires resolveu em seu art. 1": "Estabelecer a partir de 1985 um Ciclo Básico Comum $-\mathrm{CBC}^{* * * 10}$ - que constituirá o primeiro ciclo curricular dos Cursos da Universidade de Buenos Aires"11.

\section{As Novas "Experiências Curriculares" (1986-98) no Contexto Político Neoliberal}

Como surge o movimento de reformulação curricular e a partir de que liderança?

Na Faculdade de Medicina da UBA, desde 1986, surgem as primeiras discussões sobre a reforma curricular, e são implementadas novas "experiências curriculares". Ainda na gestão do decano normalizador, foram criados os Módulos de Atenção Primária (MAP) - três módulos, com 64 horas semestrais cada. A idéia central dos módulos era permitir que os alunos, desde o começo do curso, travassem contato com a prática na área de Atenção Primária, nos centros de saúde.

\footnotetext{
"* Ciclo Básico Comum é o printeiro ano dos estudos universitários, que funciona como um curso introdutório, de nivelamento e seleçaio.
} 
Em 1986, assume o primeiro decano eleito na Faculdade de Medicina, Dr. Guillermo Jaim Echeverry ${ }^{* 11}$, que deu continuidade à implantação dos MAP e à discussão sobre reforma curricular. Entre 1996 e 1997, os MAP foram suprimidos e substituídos pela disciplina Medicina Familiar, reduzindo-se aos poucos a ida dos alunos ao "campo" até eliminá-la.

Na opiniāo dos professores entrevistados, as experiências curriculares não foram avaliadas, não tiveram continuidade, e algumas foram criticadas por não ter havido capacitaçăo prévia dos docentes, e outras por terem prolongado o horário de permanência dos alunos nos hospitais.

Dentre as experiências de reforma curricular, a de maior duração, embora tenha gerado grande debate e polêmica, foi a do denominado "Plan B", que voltamos a citar adiante.

A Faculdade de Medicina da UBA, por vários anos durante o governo do presidente Carlos Menem -, teve como decano o Dr. Luis Nicolas Ferreira. Em seu mandato, gerouse muita polêmica, e foram propostas mudanças curriculares muitas vezes contrárias e incoerentes com as determinações do estatuto interno da UBA.

As duas gestões do decano Dr. Luis Nicolas Ferreira na Faculdade de Medicina da UBA, entre 1990 e 1998, foram marcadas pelo desejo de restrição do ingresso de alunos por ano na **faculdade ${ }^{12}$, tema central e polêmico na UBA e nas universidades públicas argentinas em geral (houve e há um debate interno e externo à faculdade, que registramos nas entrevistas realizadas e na leitura dos principais jornais argentinos). Neste sentido, podemos dizer que sua administração tentou dar conta da agenda política neoliberal em relação à limitação de ingresso de alunos na universidade.

Durante o período em que foi decano, o Dr. Ferreira conciliou o cargo com a presidência da Associação de Faculdades de Ciências Médicas da República Argentina (Afacimera) e da Federação Panamericana de Faculdades e Escolas de Medicina (Fepafem). No período em que presidiu tais instituições, foram realizadas atividades conjuntas com o Ministério de Cultura e Educação, através da Secretaria de Políticas Universitárias (SPU), criada pela Lei de Educação Superior. Uma das atividades foi a elaboração de documentos que estabeleceram que o curso de medicina deve ser considerado um "curso de risco" e, por esse motivo, propõem a criação de standards para o credenciamento de todos os cursos de medicina do país.

"Recentemente, o Dr. Guillermo laim Echeverry foi eleito o novo reitor da Universidade de Btrenos Aires, em abril de 2002, para substituir o reitor Oscar Schuberoff, que esteve à frente do cargo por 12 anos.

"Em lioro publicado pela Faculdade de Medicina, resultado das fornadas "Politica de Formaghlo de Recursos Humanos em Saúde", em 1991, o decano Ferreira publicou um artigo em que critica a excessiva quantidade de alunos na faculdade co ingresso irrestrito.
Desde 1996, um grupo de trabalho, composto por profissionais das duas instituições citadas, SPU e Afacimera, se dedicou a elaborar os padrões para "acreditação" (ou credenciamento), com o intuito de que os cursos de medicina do país desenvolvessem reformulações que atendessem a tais standards, para "melhorar a qualidade da educação médica e adequação aos requerimentos da Lei" e homologar normas no âmbito do Mercosul ${ }^{13}$. E, ainda, pretendendo estabelecer "um marco de referência levando em conta as políticas e reformas do setor, os padrões de exercício profissional, o funcionamento dos serviços de saúde, as normativas vigentes, os processos de integração das economias regionais $(\ldots)^{\prime \prime 13}$.

A partir da atuação dessas instituições, percebemos que tais propostas estiveram inter-relacionadas com as tentativas de reformulação curricular do período. E que as modificações implementadas no currículo de medicina durante a gestão do decano Ferreira foram influenciadas pelas discussōes do Mercosul Educativo.

Uma das atividades do Mercosul Educativo tem sido a criação de standards para os cursos de título universitário dos países do Mercosul. Os primeiros cursos escolhidos foram Agronomia, Engenharia e Medicina, tendo a Comissão Técnica de Educação Superior, o Grupo de Trabalho de Especialistas em Credenciamento e Avaliação e as Comissões Consultivas de Agronomia, Engenharia e Medicina, em reuniōes periódicas, estabelecido os standards ${ }^{14}$.

A seguir, passaremos a relatar a controvertida proposta de reforma curricular que foi o chamado "Plan B".

Em 1992, foi elaborada uma proposta de modificação no currículo que gerou impacto e muita discussão, pois teve como premissa a criação de um exame de ingresso. A idéia trazia poucas variações nas disciplinas e uma proposta metodológica baseada nas atividades práticas.

Mas, como o Conselho Superior aprovou a proposta (que é a do currículo até o momento em vigor) e não aprovou a implementação de um exame de ingresso, foi aplicado, em 1993, um plano piloto, o Plano B ("Plan B"*). A intenção era provar, com o plano piloto, que a reformulação curricular só poderia ter sucesso se fosse reduzido o número de alunos por ano.

Com uma carga horária maior, os alunos que participaram do "Plan B" haviam tido contato com pacientes em hospital desde o primeiro período do curso, e o ensino era tutorial. Um dos objetivos era integrar o Ciclo Biomédico ao Clínico desde o começo do curso e demonstrar que a redução do número de alunos significaria uma melhora na qualidade do ensino. Mas

\footnotetext{
* Plan de estudios" em espanhol significa grade curricular. Mas, neste caso, 'Plan B' se refere a uma proposta curricular. Utilizaremos a palavta original em espanhol no decorrer do texto.
} 


\title{
Quadro 1
}

Principais Modificações Propostas no "plan B" (1992/1993-2001)

\section{PROPOSTA PILOTO}

\author{
Carga horária $\begin{cases}-1.818 \mathrm{~h} & \text { Ciclo Biomédico } \\ -3.446 \mathrm{~h} & \text { Ciclo Clínico } \\ -2.604 \mathrm{~h} & \text { internato }\end{cases}$
}

Contato dos estudantes com pacientes no hospital desde o $1^{2}$ periodo

\author{
Processo ensino-aprendizagem - Tutorial \\ - Interdisciplinar \\ - Integração do Ciclo Biomédico com o Clínico desde o $1^{\circ}$ período
}

$\mathrm{N}^{\circ}$ de alunos: 100 por ano: selecionados pelas médias mais altas no $\mathrm{CBC}$ (Ciclo Básico Comum)

o "Plan B" foi muito criticado, e a experiência foi interrompida em 1998, tendo a última turma terminado o curso em $2001^{* 12}$.

$\mathrm{O}$ "Plan B" foi previsto para atender a 100 alunos, e coexistiram dois currículos paralelamente por cerca de oito anos. Em 2001, formou-se a última turma que participou da experiência, e foi garantido o direito de terminar o curso na modalidade iniciada, mesmo tedo sido o plano piloto derrogado desde 1998.

Em 1995, durante a segunda gestão do decano Dr. Luis Ferreira, criou-se o Ciclo Pré-Universitário de Ingresso (CPI), amparando-se na Lei de Educação Superior de 1995 ( $\mathrm{N}^{\circ}$ $24.521 / 1995)$, que, no seu artigo $N^{\circ} 50$, estabelece que "nas universidades com mais de cinqüenta mil (50.000) estudantes, o regime de admissão, permanência e promoção dos estudantes será definido ao nível de cada faculdade ou unidade acadêmica equivalente". Porém, a Universidade de Buenos Aires, através de seu reitor, não tinha acatado a Lei, e criou-se uma situação de conflito entre a faculdade de medicina e a reitoria. Muitos alunos foram prejudicados por vários anos, pois a Reitoria não concordava em emitir os diplomas de medicina para alunos que tivessem cursado o CPI em vez do CBC. Em 1998, foi derrogado o CPI.

Após a experiência do Plan B e do Ciclo Pré-Universitário de Ingresso $-\mathrm{o} C P I$ para substituir $\mathrm{O} \mathrm{CBC}^{*}{ }^{10}$, que não foi

\footnotetext{
"As criticas à experiência estiveram inseridas em disputas politicas e repousaram no fato de o decano que impulsionou a implantaçio do projeto ter, tanbém, implenentado uma experiéncia de modificaçalo na forma de ingresso dos alunos de medicina diferente da do resto da universidade de Buenos Aires. Especificamente com relagilo ao plano piloto, entre as criticas recebidas pela comissilo que ataliou a experiência (e professores e alunos entrevistados): foram selecionados os alunos com melhores médias e nào ao açaso; năo houve um grupo controle da experiência, já que o número de alunos que continuou com o curriculo "normal" era muito superior ao do Plan B (dificultando qualquer comparagulo), e, portanto, nio se poderia considenar a experiéncia para aplicar ao grupo todo de alunos.
}

uma reformulação curricular apenas para o curso de medicina, mas para toda a faculdade de medicina - , a seguinte reformulação curricular elaborada não foi implementada. Passamos a relatar o processo a seguir.

\section{Proposta de Reformulação Curricular de 1999}

A gestão do decano Dr. Salomón Schächter (1998-2000 impulsionou a reformulação curricular. Em seu discurso pronunciado no dia 27 de março de 1999, para apresentar o anteprojeto do "Cambio***, Curricular", deixa claro que a reformulação curricular seria uma prioridade de sua gestão, em concordância com os claustros. E, pela Resolução de 25/9/98, criou um Grupo de Trabalho para fazer um estudo e formular um anteprojeto. $\mathrm{O}$ grupo era integrado por professores dos departamentos de medicina, pediatria, anatomia, fisiologia, humanidades médicas, secretaria de educação médica, etc. ${ }^{16}$.

Foi solicitado a esse grupo que, no prazo máximo de seis meses, apresentasse um anteprojeto de reforma curricular do Curso de Medicina. Depois de uma série de reuniões semanais, desde outubro de 1998, foi entregue, em março de 1999 , um documento de proposta de reforma curricular.

Como parte de um processo de reformulação curricular do Curso de Medicina, criou-se, pela resolução do decano $\mathrm{N}^{\circ}$ 119/00, uma Comissão Mista com o objetivo de analisar o anteprojeto do novo currículo e discutir os mecanismos de instrumentação do mesmo ${ }^{17}$.

Uma das primeiras atividades desenvolvidas pela Comissão foi a implementação de um Programa de Formação Do-

\footnotetext{
*O Ciclo Básico Comum ć o primeiro ano dos estudos unibersitários da UBA, que funciona como um curso introdutório, de nivelamento e selepio

"'A palavra "cambio" em espanhol significa mudança e, neste caso, $e$ utilizada para denomina as reformas ou reformulaçles curriculares.
} 
cente, coordenado pela pedagoga Amanda Galli, professora da Secretaria de Educação Médica, que este à frente de uma equipe de pedagogas. O Programa, destinado à formação de professores e auxiliares docentes, desenvolveu-se com o objetivo de oferecer uma oportunidade de reflexão sobre as tendências atuais em Educação Médica e de fortalecer algumas habilidades docentes específicas.

Segundo o "Documento Preparado pelo Grupo de Trabatho sobre Mudança Curricular no Curso de Medicina"16, a convocatória obteve uma resposta maior do que a esperada, tanto nas Jornadas para Professores, como nas Oficinas para a Formação de Tutores.

Como resultado do período de trabalho das Comissões ad hoc criadas para avaliar e definir as unidades temáticas correspondentes ao $3^{\circ}$ ano do novo currículo (Neurociências; Ação dos Fármacos; Mecanismos Gerais da Lesão; Bases Fisiológicas e Bioquímicas das Doenças; Meio Ambiente, Agressão e Defesa), foram entregues os relatórios correspondentes, cujos delineamentos foram postos à disposição dos interessados, para consultas e opiniões.

Por outro lado, se conformaram as comissões responsáveis pela discussão das unidades temáticas correspondentes ao $4^{2}$ e $5^{\circ}$ anos do urso de medicina e que trabalharam em seus delineamentos gerais. Os módulos foram os seguintes: Grandes Entidades Clínico-Cirúrgicas; Relação Médico-Paciente; Doença e Saúde da Mulher, Doença e Saúde da Criança; Os Problemas Médicos e a Tomada de Decisão; Farmacologia e Terapêutica; Epidemiologia Clínica; Economia e Saúde; Trauma e Emergência; Humanidades Médicas; Ciências Sócio-Sanitárias.

No discurso do decano Salomón Schächter de 27 de março de 1999, estava claramente estabelecida a necessidade de reformular o currículo da faculdade de medicina dentro dos parâmentros estabelecidos pela Afacimera (Associação de Faculdades Médicas da República Argentina, cujo presidente era o Prof. Dr. Luis Ferreira), Coneau (Conselho Nacional de Avaliação e Credenciamento Universitário), Lei de Educação Superior e Mercosul:

"Para poder ser credenciado de acordo com os critérios definidos pelo Ministério de Cultura e Educação em consulta com o Conselho de Universidades com base em um perfil mínimo de credenciamento. Para obter uma categorização digna que deverá obter-se de acordo com os perfis definidos pela Coneau (A, B ou C) (...). Para fortalecer a posição de nosso país em toda futura negociação no reconhecimento de equivalências para o exercício de nossa profissão no Mercosul."
No documento preparado pelo "Grupo de Trabalho sobre Reforma Curricular no Curso de Medicina" ${ }^{\text {"16 }}$, também se percebe a vinculação com as determinações da Afacimera, Coneau e Lei de Educação Superior e Mercosul:

"As Faculdades de Medicina da Argentina que compõem a Afacimera fizeram recentemente uma proposta sobre o perfil profissional, incumbências do título de médico e conteúdos mínimos do ensino. Este documento foi aprovado em forma geral pelo Conselho de Universidades e, considerando que será aplicado pela Coneau como base para a avaliação das Faculdades de Medicina prevista pela Lei de Educação vigente, deve ser tomado como base absolutamente necessária para qualquer modificação curricular que se tente realizar"16.

É interessante observar que, considerando a Lei de Educação Superior Argentina como uma demonstração das transformações neoliberais sofridas na educação desse país na década de noventa, a proposta de reformulação curricular apresentou clara concordância com tais princípios e obedece às tendências que enfatizam a avaliação e o credenciamento como centrais.

O grupo de trabalho que elaborou a proposta de reformulação curricular considerou que, para levar adiante o processo de transformação do modelo educativo e prática docente, seria fundamental elaborar um currículo coerente com as tendências vigentes, definir e implemenar uma estratégia para o desenvolvimento do corpo docente e implementar uma reforma acadêmico-administrativa.

Como um dos pontos centrais da proposta citada, estava a crítica, mais uma vez, ao alto número de estudantes na faculdade e à baixa proporção entre professores contratados (com formação docente) e auxiliares sem remuneração. Aí estão alguns dos problemas centrais da UBA, debatidos tanto nas faculdades quanto nos meios de comunicação e que apareceram nas outras propostas de reformulação: a restrição do número de alunos por ano, com o estabelecimento de um exame de ingresso (não está previsto no estatuto da UBA) e o problema do número de professores (não são abertas vagas para concursos proporcionais ao incremento do número de alunos a cada ano). De acordo com o censo realizado no ano 2000 , cerca de $30 \%$ dos professores da universidade são $a d$ honorem*, ou seja, trabalham sem remuneração.

O Quadro 2 apresenta o esquema da reformulação curricular proposta em 1999.

\footnotetext{
"Em geral, os profissionais que exercem a docéncia nas chamadas 'aulas práticas' sào recémformados, que não passam por concurso e não recebem nenhum tipo de salário ou pagamento além da experiência que acumulam (as aulas teóricas sào oferecidas de forma magistral pelos titulares das cadeiras ou adjuntos).
} 
Quadro 2

Reformulação Curricular 1999 (ênfase: avaliação, credenciamento, flexibilizaçãso da grade curricular)

\begin{abstract}
Críticas ao modelo vigente: Separação em dois ciclos (Básico e Clínico) com pouca articulação entre si, dificultando a aprendizagem e limitando a capacidade de recuperar informaçōes pertinentes necessárias para solucionar problemas da clínica.
\end{abstract}

Excesso de conteúdos e rigidez da grade curricular.

Dicotomia entre as aulas teóricas e práticas e tardio contato com doentes $\left(4^{\circ}\right.$ ano do curso).

Separaçăo entre ensino, assistência $\mathrm{e}$ pesquisa.
Fundamentos do modelo educativo

Ensino integrado $\rightarrow$ níveis de complexidade "em espiral".

"Reengenharia" do corpo docente $\rightarrow$ aprendizagem centrada no interesse do aluno.

Aprendizagem baseada em problemas $\rightarrow$ pequenos grupos com tutores facilitadores.

Estudo independente.

Avaliações formativas $\rightarrow$ acompanhamento e orientação do aproveitamento.

Avaliaçōes unificadas $\rightarrow$ verificação e controle da aprendizagem.

Desenvolvimento de instrumentos de avaliação $\rightarrow$ aspectos cognitivos, análise e síntese diante de de problemas mais complexos, atitude colaborativa e humanista.

Avaliaçăo sistemática das competências clínicas.

Perfil do médico da proposta

Empregar o método científico e o trabalho de equipe.

Reconhecer e assumir a importância da pesquisa básica, clínica e socioepidemiológica na prática médica.

Compreender as necessidades de saúde das pessoas nos aspectos físicos, psicológicos,

familiares, de trabalho e econômicos.

Promover a saúde no núvel individual e comunitário.

Diagnosticar os problemas de saúde da população e dos grupos de risco.

Elaborar, implementar e avaliar programas de cuidado à saúde no primeiro nível de atenção (APS - Atenção Primária em Saúde).

Prevenir, diagnosticar e tratar as doenças prevalentes e resolver as urgências no primeiro nível de atenção de forma efetiva, eficiente e humanitária.

Fazer diagnóstico presuntivo de patologias não habituais e atuar cooperativamente e interdisciplinarmente, articulando a estratégia da interconsulta e/ou derivaçāo.

Reconhecer suas próprias limitações e, frente a situaçōes complexas, estar habilitado a atuar cooperativamente.
A proposta de reformulação curricular de 1999 aborda, então, a questão posicionando-se a favor do estabelecimento de um número restrito de vagas por ano para o curso de medicina. Estabelece como condição fundamental para a adequada implementação da proposta a redução do número de estudantes que ingressem no $2^{\circ}$ ano para 1.400 alunos (o primeiro ano é o Ciclo Básico Comum). Ao desenvolver e apoiar na proposta a redução do número de alunos, o decano e sua equipe se posicionaram frente a um dos grandes debates das universidades públicas argentinas, o que representou uma grande polêmica no âmbito político-universitário (que comentaremos a seguir).

Em dezembro de 1999, o decano foi pressionado a renunciar ao cargo, e o processo de reformulação curricular mudou de rumo e liderança. Tal mudança foi um reflexo da forma de governo da UBA. Faremos uma relato da mudança, a fim de demonstrar as inter-relações da política universitária com as reformulações curriculares, especificidade do caso que não pode ser negligenciada.

\section{Mudança de Decano: Qual a Sua Influência na Reformulação Curricular?}

A nova gestão propôs uma reformulação curricular, começando um novo processo sem dar continuidade ao que vi- nha sendo feito antes. Por mais que tenham sido feitas críticas ao processo anterior - não ter sido democrático; inviabilidade de implantação por falta de recursos; elitização do curso com a restrição do ingresso, etc. - , opinamos que a necessidade de mudança de rumo da reformulação esteve vinculada prioritariamente à mudança política da direção da faculdade. Por isso, consideramos necessário descrever a mudança de direção, uma vez que aponta para a compreensão do chamado governo das universidades públicas argentinas (instâncias de participação e decisão) e demonstra características importantes percebidas na reformulação curricular da medicina.

Após duas gestões, entre 1994 e 1998, o Dr. Luis Ferreira propôs um candidato nas eleições dé março de 1998, o Dr. Salomón Schächter, que as venceu, porém não seguiu a forma "ferreirista"* de administração e direção da faculdade de medicina e implantou uma forma pessoal de administração.

\footnotetext{
"Os entrevistados, em sua maioria (salvo os correligionários), se referem à gestalo do decano Ferreira como identificada com a politica menemista, que tem como caracteristica acatar e aplicar as politicas neoliberais. No caso da medicina, identificam-se medidas privatizantes da saúde, valorizaçlo das especialidades médicas e pritadas em detrimento da saúde püblica, aplicapaino da Lei de Educaçăo Superior c adaptaçado do curriculo mádico a lei.
} 
Segundo epoimentos de professores e representantes estudantis entrevistados de setembro de 2000 a agosto de 2001, a mudança de decanato se deu da forma descrita a seguir.

Aparentemente, o Dr. Salomón Schächter não estava vinculado às idéias do Dr. Ferreira e delineava uma nova política de açōes para a Faculdade de Medicina - fundamentalmente, a reforma curricular e a proposta do limite de entrada de 1.400 alunos para o $2^{\circ}$ ano do curso. Esta realidade se transformou em dezembro de 1999, quando se realizaram as eleições de representantes estudantis ${ }^{* 18}$ e ganhou "a maioria" dos alunos do partido da "Aliança". Desde então, houve pressão para a destituição do decano. As forças políticas estavam confrontadas, já que o decano, Dr. Schächter, e o secretário acadêmico, Dr. Marcelo Torino, eram considerados "herança" da gestão de Ferreira, portanto menemistas, e todos os outros postos do Conselho Diretivo eram ocupados por membros da Aliança (e da chamada "agrupação estudantil" Fraja Morada, ambas vinculadas ao Partido Radical).

No início de agosto, o secretário acadêmico, Marcelo Torino, foi destituído "pela maioria" da Aliança, o que desembocou na crise que culminou com a renúncia de Schächter. Seu mandato, que se estenderia de 9 de março de 1998 a 2001, terminou em 24 de agosto de 2000 . No dia 25 de agosto, foi eleito o candidato da Aliança, Salomón Muchnik ${ }^{19}$.

A partir da gestão do novo decano, a proposta de reformulação curricular foi interrompida e teve início um novo processo de discussão e elaboração da proposta descrita a seguir.

\section{A Atual Proposta de Reformulação Curricular (2000- 2001)}

A nova proposta é impulsionada pelo novo decano e pelo secretário acadêmico.

Em 14 de dezembro de 2000, foi realizada a primeira reunião, chamada "Jornada de reflexão sobre avaliação permanente e reforma curricular". Com a participação de professores e estudantes da Faculdade de Medicina da UBA, da reitoria da UBA e de professores externos à UBA (e até ao país), foram discutidos os temas: avaliação, ingresso, permanência, egresso, internato rotatório e residência. A partir da reuniăo seguinte, em abril de 2001, passaram a ser realizadas reuniões quinzenais (e algumas vezes semanais) para ampliar os temas da primeira jornada, sob a coordenação da subsecretária de Planejamento Educativo, professora Nidia Schuster.

'Os representantes estudantis se renobam a cada ano, os representantes dos professores a cado quatro anos, e os graduados a cada dois anos. O reitor é eleito a cada quatro anos pela assembléia teniversitária.
Alguns dos temas das reuniões seguintes foram: ciência, saúde e educaç o superior; aprendizagem baseada em problemas e centrada no estudante; o conhecimento básico na prática médica; integração no ensino da medicina; a educação médica e a educação; metodologia do ensino, objetivos, propostas e inovações; capacitação docente e novas metodologias de ensino; alternativas de formatos curriculares; reformulação curricular e experiências recentes; modificação estrutural ou não estrutural, flexibilidade curricular, módulos integrados, seminários optativos; o problema do ingresso numa eventual reforma dos estudos; microbiologia médica e reforma curricular; bases conceituais das reformas curriculares; integração curricular, integração entre cursos na área de saúde; atenção primária, doenças infecciosas que geram marginalidade na infância; módulos de atenção primária (MAP); uso racional das novas tecnologias no ensino; inclusão da atenção primária da saúde nos currículos; propostas de reformulação curricular de ginecologia; a experiência da saúde mental; integração do ciclo clínico com o ciclo biomédico; internato rotatório; experiência de internato no hospital de pediatria; avaliação por resolução de problemas do departamento de pediatria; avaliação da aprendizagem; flexibilidade curricular para mudanças nos cursos; avaliação do ensino, avaliação da aprendizagem, permanência do aluno nos cursos, ingresso e egresso; avaliação diagnóstica dos conhecimentos do ciclo biomédico na unidade hospitalar, resolução de problemas, patologia II; o ensino das humanidades médicas nas universidades argentinas; modelo médico-antropológico integral; formação do médico e sua inserção social; universidade e política; pediatria: experiência docente de vinte anos; qualidade educativa na UDH (Unidade Docente Hospitalar); ensino e estilos de pensamentos e aprendizagem; avaliação diagnóstica dos conhecimentos do ciclo biomédico na unidade hospitalar; universidade e política.

Desde o final de 2000 e durante todo o ano de 2001, a secretaria acadêmica da faculdade de medicina organizou as "Jornadas para el Cambio Curricular" com a idéia de que fosse um fórum aberto de auto-avaliação institucional. Paralelamente, criou a Subsecretaria de Planejamento Educativo, com a intenção de sistematizar as contribuições participativas da comunidade educativa envolvida.

O processo de discussão inicialmente se propôs avaliar o material elaborado pelas comissões da reformulação anterior, mas efetivamente não foi feito nenhum trabalho nas jornadas, nem houve aproveitamento da experiência prévia. A única referência foi através de críticas: o processo anterior não havia sido democrático, a proposta não tinha levado em conta a real capacidade e realidade da faculdade de medicina, já que 
dependia de uma estrutura de bibliotecas e de uma quantidade de tutores preparados para trabalhar em pequenos grupos de que a faculdade não dispunha. Também consideraram que os recursos não teriam sido suficientes para implementar a reformulação proposta.

Nas primeiras jornadas, alguns professores que tinham participado ativamente do processo anterior pareciam estar frustrados e perguntaram se algo seria aproveitado da experiência anterior. As respostas naquele momento não pareceram convincentes, e, nos comentários feitos durante os intervalos, eles lamentaram que cada gestão sempre precise recomeçar do zero e que tal atitude provoca descrédito por parte dos professores interessados em participar.

Observamos que, no decorrer das reuniōes, poucos professores que participaram das comissões de reformulação curricular na gestão do decano Schächter compareceram. Mesmo assim, alguns dos que foram às reuniões da atual gestão haviam feito parte da lderança do processo anterior. Isso demonstra um interesse real pelas discussōes e modificaçōes de caráter pedagógico, independentemente da linha política da atual liderança da faculdade*.

A coordenação das Jornadas de Reformulação Curricular (decano, secretário acadêmico e subsecretária de Planejamento Educativo), buscando o consenso dos que participaram, concluiu que "toda reformulação inovadora no processo de ensino requer atualizações organizativas em função de um diagnóstico e uma avaliação permanente das atividades acadêmicas" ${ }^{\prime 20}$. A secretaria acadêmica, através da subsecretaria recentemente criada, detectou núcleos temáticos que consideram as debilidades a serem analisadas para gerar um processo de "atualização curricular" viável na facldade.

$\mathrm{Na}$ opiniăo dos coordenadores (secretário acadêmico e subsecretária de Planejamento Educativo), os processos de reformulação curricular massiva e de raiz, quando analisadas as possíveis resistências, são fadados ao fracasso. Consideram prioritário, então, "assumir as dificuldades a partir de sua identificação e descrição, analisar os problemas utilizando os indicadores para sua medição e avaliar as mudanças que possam gerar novas medidas a implementar". Optaram pela promoção do que chamaram "motores de câmbio" (motores de mudança), com a idéia de pequenas modificaçōes em vez de uma modificação radical do currículo. Para as modificações no currículo que a atual gestão da faculdade de medi-

\footnotetext{
"Com esse comentírio qqueremos reforçar a idéia de que os processos de reformulaçåo curricular tề obedecido a mais de uma lógica, conciliando tendências pedagógicas e polificas. Ou seja, cmbora a mudança de direpalo tenha significado a interrupgăo de um processo para iniciar um novo, isso não impediu a participação, nas reuniōes, de professores de outros grupos poiticos e mesmo de professores sem identificạ̧̄o com nenhuma das duas linhas de gestão.
}

cina pretende realizar, foi considerado prioritário criar, sob a dependência direta do decanato, um Departamento de Avaliação Permanente e Reformulação Curricular. Para isso, há um projeto de resolução em andamento, a ser aprovado pelo Conselho Diretivo da faculdade. O departamento, quando criado, contará com um orçamento específico, proveniente do subsidio do Banco Interamericano de Desenvolvimento (BID), através do Programa de Atenção Primária em Saúde (Proaps)**.

OQuadro 3 apresenta a lista das propostas para os núcleos temáticos do departamento a ser criado.

\section{QUADRO 3}

Proposta para os núcleos temáticos do Departamento de Avaliação Permanente e Reformulaçāo Curricular

Capacidade educativa da faculdade $\rightarrow$ aprofundar o relatório elaborado em setembro de 1999.

- Ações dos departamentos docentes da faculdade $\rightarrow$ detectar as necessidades de apoio e assessoramento nas atividades.

- Nível de educação básica e habilidades metodológicas dos estudantes $\rightarrow$ diagnóstico conjunto com CBC.

- Apoio à implementação de oficinas de atualização $\rightarrow$ melhorar a integração curricular (carreira docente e de auxiliares).

- Avaliar a coerência entre o perfil profissional requerido pela socidade $\mathrm{e}$ as do modelo curricular do curso.

- Analisar e avaliar alternativa para flexibilização curricular $\rightarrow$ gerar um espaço para cursos optativos.

- Levantamento das pós-graduações $\rightarrow$ enriquecer a atualização científica dos docentes e incentivar os estudantes.

- Levantamento das necessidades de atualização bibliográfica, de recursos materiais, didáticos e equipamento $\rightarrow$ facilitar futuros projetos de inovação curricular.

- Levantamento das necessidades de atualização técnica da Subsecretaria de Tecnologia Educativa e para a Biblioteca da Faculdade $\rightarrow$ atualização de recursos bibliográficos, multimídia e informáticos, e melhoramento de infra-estrutura.

"O Ministério da Saúde argentino, através da Subsecretaria de Atenção Primária e juntamente com o Banco Interamericano de Desentolvimento (BID), langou o Programa de Reforma de Atençalo Primária da Sauide (Proaps), a ser desenzolvido em cinco anos, periodo durante o qual o organismo de crúdito internacional faná um empréstimo de 120 milhồes de pesos. O Proaps incorpora a construçẫo de notos centros de saúde e seu equipanento, assim como o equipamento dos consultórios dos médicos de "cabeccira". Nas palavras do então ministro da Saúde argentino, "se apoiará economicamente essas casas de altos estudos com of fim de ampliar e melhorar seus curriculos e orientá-los para a formaģâo de médicos de $1^{*}$ nivol de atençūo". 
Esses foram os pontos centrais levantados a partir das discussōes travadas nas Jornadas. Alguns pontos são coerentes com a proposta de reformulação anterior, e outros se baseiam justamente em sua crítica. No ultimo item, por exemplo, a questāo da atualização e melhoramento dos recursos da bilbioteca da faculdade é reflexo da crítica feita à reformulação anterior: nela, a metodologia central seria baseada no ensino por resolução de problemas sem que a faculdade contasse com lugares e recursos para oferecer aos alunos nas pequisas individuais, fundamentais à aplicação da metodologia.

A proposta de reformulação, até o momento, está focalizada na criação do Departamento de Avaliação Permanente e Reformulação Curricular, no qual serão implementadas as ações para gerar os "motores de cambio". É interessante observar que tal criação está vinculada à possibilidade de receber os recursos do BID, através do Proaps. Isso está conectado com o que descrevemos no início deste artigo sobre a influência dos orgãos de financiamento internacionais em linhas de atuação nas áreas de educação e de saúde nos países da América Latina.

Iriart \& Waitzkin ${ }^{21}$ descrevem que, no relatório de 1993 sobre o Desenvolvimento Mundial, "Investir em Saúde", o Banco Mundial argumentou que a ineficácia dos programas do setor público dificultava a provisão de serviços, assim como a redução da pobreza. O Relatório aconselha outorgar à população incentivos para a compra de seguros privados, a rivatização de serviços públicos, a promoção da competência no mercado e a ênfase na atenção primária e na prevenção. Através deste documento e das políticas subseqüentes, segundo as críticas formuladas em toda a América Latina, o Banco Mundial vem promovendo a ideologia de que "a saúde é uma questão privada, e sua obtenção um bem privado". "Especificamente o Banco Mundial apóia iniciativas de atenção gerenciada que transferem as instituições públicas de atenção da saúde e os fundos da seguridade social para a administração ou para a propriedade privada. Estas iniciativas trazem consigo novos empréstimos e o conseqüente crescimento da divida externa dos países que participam". Ainda segundo os autores, outras agências multilaterais de empréstimo participam das mesmas estratégias de reforma, a exemplo do Banco Interamericano de Desenvolvimento*.

"O Banco Interamericano de Desenvolvimento oferece linhas de crédito para sercm usadas nas mudanças das estruturas orgânicas $e$ das plantas fisicas dos hospitais que são consistentes con a privatização. Na Argentina, o BID colaborou con o Banco Mundial, apoiando a conversalo de hospitais públicos em "hospitais de autogestäo", com os princípios da atenyslo gerenciada que exigem a competiglo destes hospilais no mercado com os privudos, para atender aos pacientes cobertos pela seguridade social.

\section{CONSIDERAÇÕES FINAIS}

Buscamos identificar algumas marcas, no processo analisado, da transformação pela qual o Estado passa desde a década de noventa. Percebemos que as várias propostas de modificação no currículo estiveram vinculadas às modificações do panorama mundial. A mudança na Lei de Educação Superior é um exemplo, e o aproveitamento da "brecha" na lei para propor uma modificação no regime de ingresso de alunos na faculdade de medicina a caracteriza bem. A modificação na lei produziu uma mudança muito importante num dos princípios reformistas, característicos das universidades argentinas: o ingresso democrático e sem limite de vagas para as universidades públicas.

Por isso, neste trabalho, a percepção da universidade como "instância cultural" foi fundamental e significou entendê-la como um conjunto de açōes e contradições que recontaram uma história lida em sua transmissão de saberes, valores e representações. A análise cultural das universidades contribuiu com elementos importantes para compreender a crise atual das instituições de educação superior na Argentina. Segundo Marcela Mollis ${ }^{22}$, a universidade se constrói como uma instância de produção, controle e legitimação, num contextó de tensão constante entre a importância que recebe da sociedade, do Estado, do mercado produtivo e suas tradicionais funções de produção e difusão do saber.

As mudanças no Estado descritas, seus reflexos na Lei da Educação Superior de 1995 e as propostasdo Mercosul Educativo; a dinâmica interna própria das universidades públicas argentinas, herdadas da Reforma de 1918 (atravessada pela disputa política); a dimensão pedagógica na qual os profissionais da área de educação têm grande prestígio e indicam os caminhos a seguir nos processos de reformulação curricular da medicina da UBA (Currículo Baseado em Resolução de Problemas ou Currículo por Disciplinas) são alguns dos eixos presentes na realidade estudada. Cada uma dessas peças fez parte do quebra-cabeças e conformou o processo de reformulação curricular da Faculdade de Medicina da UBA por cerca de duas décadas.

No decorrer do trabalho de pesquisa, identificamos dois aspectos concomitantes no processo de reformulação curricular: um macro, da racionalidade externa, quando, no relato das diferentes tentativas de reformulação curricular, apareceu o eixo político-econômico, isto é, os vários momentos vinculados à política externa e interna da faculdade e à forma marcante pela qual interferiram nos processos descritos. $\mathrm{O}$ outro aspecto, micro, mais internalista, da racionalidade interna, se refere ao currículo diretamente e à forma como foram questionadas as modificações nas disciplinas, sua metodologia, ou seja, o aspecto especificamente pedagógico. Quan- 
to a este último aspecto, percebemos que, durante os vários processos descritos, um grupo de pedagogas trabalhou sem interrupção, independentemente das mudanças políticas dentro da faculdade. E o aspecto pedagógico teve - e continua a ter - grande importância nos processos, na racionalidade interna. Em grande parte dos processos, os profissionais da área de educação tiveram papel de liderança ou co-liderança. Mesmo que em alguns momentos os grupos tivessem diferentes composições (diferentes profissionais da área de educação trabalhando) - e que não pretendamos atribuir às pedagogas um papel neutro, "apenas técnico" nas reformulações -, não podemos deixar de observar a continuidade dessa característica que se destaca pela importância conferida a esse profissional.

A partir da identificação das duas racionalidades que interagem no processo, o desafio para a reformulação que está sendo desenvolvida é saber qual das duas lógicas predominará. Se o pedagógico e o interno das lógicas vão promover uma boa reformulação curricular para que se formem melhores médicos, preparados para trabalhar com a realidade de saúde do país, como debatido em tantas reuniões. Ou se o cruzamento com as externalidades, as questões políticas e econômicas, além de influenciar as tendências do perfil do médico, poderá novamente levar a uma reformulação que não saia do papel, da negociação política em si, sem transformar a política em ação. A universidade argentina está cruzada pelas duas lógicas.

Com esse comentário queremos reforçar nossa conclusão de que os processos de reformulação curricular têm obedecido a mais de uma lógica, conciliando tendências pedagógicas e políticas. E é dentro do marco interno da universidade que se insere o aspecto pedagógico, as dinâmicas e disputas pelas diferentes linhas pedagógicas a seguir.

Há uma dimensão da refomulação estudada que está vinculada às mudanças no Estado, mas também há uma dimensão própria da universidade, e isso ajuda a entender por que o aspecto pedagógico da reformulação curricular pode ser analisado à parte.

$\mathrm{Na}$ área médica, foram definidas as diretrizes curriculares a serem seguidas por todas as faculdades de medicina dos países membros do Mercosul. A que demanda atenderão tais diretrizes e até que ponto serão implementadas por todas as faculdades, públicas ou privadas?

No caso da Faculdade de Medicina da UBA, cada processo de reformulação obedeceu a uma lógica, dependendo das lideranças que o impulsionaram. No processo anterior, interrompido no final do ano 2000, a idéia era seguir as indicações do Mercosul Educativo com relação às diretrizes curriculares. Em geral, o trabalho acompanhou as modificaçōes previstas pela Lei de Educação Superior, em coerência com os delinea- mentos dos organismos financeiros internacionais nas indicaçõoes para a América Latina.

Já no atual processo de reformulação curricular, iniciado em dezembro de 2000 , tais questões não foram discutidas cla. ramente nas reuniōes realizadas durante o ano 2001, nem foi explicitado o seguimento ou não de tais princípios.

A avaliação e o credenciamento universitários são dois pontos fundamentais para entender as tendências mundi. alizantes das políticas de educação superior na Argentina e aparecem no contexto da reformulação curricular que descrevemos. Porém, a Faculdade de Medicina da UBA, até o momento, é a única faculdade de medicina do país que não entrou no programa de avaliação do Coneau. Isso se deu em função das disputas político-ideológicas descritas. É possível que a atual direção da faculdade impulsione a avaliação, mesmo adequando-se à proposta estabelecida na Lei de Educação Superior, da qual esteve historicamente discordante (com exceção dos dois mandatos do decano Ferreira).

Nos vários processos de reformulação curricular, as definiçōes sobre o perfil profissional do médico não outorgaram pelo menos explicitamente, uma grande importância à discussão do modelo de saúde pública. Voltamos a assinalar que as transformações curriculares aqui analisadas aconteceram e acontecem num momento histórico na Argentina marcado pela ofensiva das políticas neoliberais, talvez como em nenhum outro país da América Latina. Os efeitos das políticas promulgadas pelos governos que provocaram o desmantelamento, 0 estrangulamento do orçamento e a privatização do sistema público de saúde parecem, lamentavelmente, ter seu correlato nas discussões curriculares. Elaborar um currículo e formular as políticas educativas de formação dos médicos pressupõe, em nosso entender, discutir o modelo de profissional que se quer formar e a que tipo de necessidades atenderá.

A pequena presença destes interrogantes nos processos de reformulação curricular apresentados neste trabalho, num contexto de "naturalização" da mercantilização da saúde, não significa que as definições acerca do tipo de profissional não estejam presentes nos currículos. Mas, diante da ausência de uma clara definição em torno do fortalecimento e transformação do sistema público de saúde, parece consolidar-se cada vez mais um modelo de formação médica de acordo com a mercantilização da saúde.

Frente à grave situação sanitária que atravessam milhões de cidadãos argentinos, seria muito ingênuo deixar de reconhecer o déficit real de profissionais médicos na Argentina. Isto, entretanto, não parece inquietar os atores governamentais e/ou acadêmicos que têm apostado num modelo de saúde mercantilizado. 
Num contexto de empobrecimento crescente, o mercado de trabalho médico argentino está diminuindo porque há menos distribuição de recursos, e a população que pode consumir a medicina privada é cada vez menor. A diferença está entre o mercado de trabalho e as necessidades sanitárias do pa s. E a Argentina gasta apenas $8 \%$ do PIB em saúde.

A criação de conhecimentos médicos implica a formação de profissionais inseridos em seu contexto sociocultural e de uma escola médica como um lugar de produção de conhecimentos. E de geração da consciência da necessidade de universalizar o direito à assistência sanitária pública, para reverter os perniciosos e devastadores efeitos da mercantilização da saúde.

\section{REFERÊNCIAS BIBLIOGRÁFICAS}

1. Chauí M. A universidade em ruínas. In: Trindade $\mathrm{H}$, org. A universidade em ruínas na república dos professores. Petrópolis (RJ): Vozes; 1999.

2. Gentili P. Universidades na penumbra: o círculo vicioso da precarização e a privatização do espaço público. In: Gentili P, org. Universidades na penumbra: neoliberalismo e reestruturação universitária. São Paulo: Cortez; 2001 p. 97-128.

3. Leher R. Projetos e modelos de autonomia e privatização das universidades públicas. In: Gentili P, org. Universidades na penumbra: neoliberalismo e reestruturação universitária. São Paulo: Cortez; 2001 p. 151-188.

4. Mollis M. Las políticas de reforma universitária: la lógica global y la respuesta local - el caso de la Argentina. Interface Comum Saúde Educ. 1999; 5: 75-94.

5. Mollis M, Bensimon M. Calidad de la educación superior desde una perspectiva comparada: el caso de la Argentina y los Estados Unidos. In: Casanova H, Rodriguez R, org. La Universidad Latinoamericana Modernizada. México: Siglo XXI; 1999.

6. República Argentina. Lei $N^{2} 24.521$ de 1995. Dispõe sobre a Educação Superior, 1995.

7. CONEAU. Comisión Nacional de Evaluación y Acreditacíon Universitaria. [Capturado em mar 2002] Disponivel em: http://www.coneau.gov.ar.

8. Faculdade de Medicina, Universidade de Buenos Aires. [Capturado em mar 2002] Disponivel em: <http:// www.famed.uba.ar>

9. Paviglianiti $\mathrm{N}$ et al. Recomposición neoconservadora. Lugar afectado: la universidad. Buenos Aires (AR): Miño y Dávila; 1996.

10. Mignone EF. Política y Universidad. El Estado Legislador. Buenos Aires: Lugar Editorial/IDEAS; 1998.
11. Universidade de Buenos Aires. Expediente: 29459/84. Conselho Superior. Universidade de Buenos Aires; 1984.

12. Ferreira LN. Formación de Recurso Humano y cambio curricular en la Facultad de Medicina de la Universidad de Buenos Aires. In: Faculdade de Medicina, UBA. Jornadas: política de formación de recursos humanos en salud. Buenos Aires, Prensa Medica Argentina/Facultad de Medicina-UBA; 1991 p. 107-115.

13. Morera MI, Brissón ME. "Carreras de Riesgo": el caso de la Medicina. Metodología, Procesos y Productos en la formulación de los patrones y estándares previstos por la Ley de Educación Superior. Buenos Aires (AR): AFACIMERA/La Prensa Médica Argentina; 1998.

14. Memorando de Entendimento sobre a implementação de um mecanismo para o reconhecimento de títulos de graduação universitária nos países do Mercosul. Documento elaborado na Reunião de Ministros de Educação dos países do Mercosul; 1998 (mimeo.).

15. Faculdade de Medicina. Universidade de Buenos Aires. Expediente: 507.433/92. Buenos Aires (AR): Conselho Diretivo, Faculdade de Medicina - UBA; 1992.

16. Faculdade de Medicina - UBA. Documento preparado pelo grupo de trabalho sobre reformulação curricular do curso de medicina. Buenos Aires (AR): Faculdade de Medicina, Universidade de Buenos Aires; 1999b.

17. Faculdade de Medicina - UBA. Propuesta de Cambio Curricular. [Capturado em 2000] Disponível em: http:// www.fmed.uba.ar.

18. Mollis M. La Universidad Argentina en Tránsito. Buenos Aires (AR): Fondo de Cultura Económica, 2001.

19. La facultad de Medicina elige hoy al nuevo decano. Clarin 2000; 25 ago, Educación, p. 46.

20. Faculdade de Medicina - UBA. Aportes para un cambio curricular en Argentina 2001. Buenos Aires: OMS/OPAS, 2001.

21. Iriart C, Waitzkin $H$. Atención gerenciada: ¿Exportación de riesgos?. Boletim Informativo da Faculdade de Medicina 2000 [Capturado ago 2001-mar 2002] Disponível em: http://www.fmed.uba.ar/boletininformativo.

22. Mollis M. En busca de respuestas a la crisis universitária: história y cultura. Perfiles Educativos 1995; 69: 35-40.

Endereço para correspondência

Rua General Glicério, 445/601

22245-120 - Rio de Janeiro - RJ

e-mail: liliankoifman@hotmail.com 